\title{
Non-manipulation of Patent LIMA in the Setting of Reoperative Aortic Valve Replacement in Patients with Previous Coronary Artery Bypass
}

\author{
A Zapolanski ${ }^{1}$, CE Kuschner ${ }^{1}$, CK Johnson ${ }^{1}$, G Ferrari ${ }^{1,2}$, RE Shaw $^{1}$, ME Brizzio ${ }^{1}$, JB Grau ${ }^{1,2^{*}}$ \\ From World Society of Cardiothoracic Surgeons 25th Anniversary Congress, Edinburgh \\ Edinburgh, UK. 19-22 September 2015
}

\section{Background/Introduction}

A patent left internal mammary artery (LIMA) graft challenges the protective effects of cold blood cardioplegia in patients undergoing re-operative aortic valve replacement (AVR).

\section{Aims/Objectives}

This study presents the results of our approach to myocardial protection in a series of consecutive patients with previous coronary artery bypass $(\mathrm{CAB})$ undergoing $\mathrm{AVR}$.

\section{Method}

Between 2006 and 2014, 72 patients met criteria for inclusion. Out of these 72, 59 had previous $C A B$ and 13 had $\mathrm{CAB}+\mathrm{AVR}$. The surgical procedures performed in these series included 50 AVR and 22 AVR + CAB. Myocardial protection was delivered using mild systemic hypothermia and continuous cold blood retrograde and intermittent antegrade cardioplegia, avoiding any manipulation of the LIMA graft. Pre-operative demographics, operative characteristics, in-hospital complications and 30-day mortality were collected according to Society of Thoracic Surgeons (STS) standards.

\section{Results}

The cohort was predominately male (89\%) and diabetic (58\%) with an average age of $74 \pm 8$.3. Patients observed improved outcomes compared to STS predicted risk in Mortality $(2.7 \%$ vs $6.5 \%)$, Stroke ( $1.4 \%$ vs $2.6 \%)$, Re-operation (6.8\% vs $11.2 \%$ ), Prolonged Ventilation (9.6\% vs $21.4 \%)$, Renal Failure (1.4\% vs $10.0 \%)$ Deep Sternal Wound Infection (0.0\% vs $0.8 \%)$ and Length of stay $>14$ days $(2.7 \%$ vs. $32.5 \%)$. More patients had a length of Stay $>6$ days than Predicted (46.6\% vs $21.6 \%$ ). The STS does not provide a predicted risk for myocardial infarction. The actual rates of complications were lower than expected in five of the provided categories. The 1-, 3-, 5-, and 8-year mortality rates were $4.5 \%$ $(\mathrm{n}=3 / 69), 9.8 \%(\mathrm{n}=5 / 51), 20.0 \%(\mathrm{n}=6 / 30)$, and $45.5 \%(\mathrm{n}=5 / 11)$ respectively.

\section{Discussion/Conclusion}

In this series avoiding the manipulation of a patent LIMA graft was associated with a low morbidity and complication rate, including myocardial infarction, when compared to the predicted STS risk. This has become our preferred approach when performing re-operative surgery on patient with patent LIMA.

\section{Authors' details}

${ }^{1}$ Valley Heart and Vascular Institute, Department of Cardiac Surgery, Ridgewood, NJ, USA. ${ }^{2}$ University of Pennsylvania, Department of Surgery, Philadelphia, PA, USA.

Published: 16 December 2015

doi:10.1186/1749-8090-10-S1-A107

Cite this article as: Zapolanski et al:: Non-manipulation of Patent LIMA in the Setting of Reoperative Aortic Valve Replacement in Patients with Previous Coronary Artery Bypass. Journal of Cardiothoracic Surgery 2015 10(Suppl 1):A107. 